Oceanography is starting a new section entitled "The Future of Oceanography". This section will allow young scientists (those who recently received or are about to receive their Ph.D.s) to introduce themselves and their research to the oceanographic community. Each scientist will be given about a page (including one figure) to describe some facet of his/her Ph.D. work. A couple of these presentations will be included in each issue.

In order for a scientist to be considered, a TOS member must recommend him/ her. If you are interested in nominating a young scientist, please send a letter to the editor or an associate editor with the name and present address of the nominee.

\title{
Bomb Tritium IN THE DeEP NoRTh AtLantiC
}

\author{
By Scott C. Doney
}

\begin{abstract}
$\mathrm{T}_{\mathrm{H}}$ HE LARGE-SCALE CIRCULATION patterns in the deep ocean are difficult to measure directly, and much of what is known about deep ocean flow has been deduced from the distributions of hydrographic tracers (e.g. salinity, oxygen, nutrients). Hydrographic tracers, however, tell us little about the rates of the processes involved, and over the last 25 years, oceanographers have increasingly turned to transient tracers-radiocarbon, tritium, and more recently the chlorofluorocarbons-in an attempt to estimate the time-scales of circulation in the deep ocean. As part of my thesis research, I have used bomb-tritium data from the Transient Tracers in the Ocean (TTO) program to quantify the ventilation or replenishment rates for deep water in the North Atlantic.

Tritium, a radioactive isotope of hydrogen $\left(\mathrm{H}^{3}\right)$ with a 12.45 -year half-life, is found in the environment primarily as tritiated water (HTO). Atmospheric testing of fusion weapons in the late 1950 s and early 1960 s released a large pulse of tritium into the atmosphere, overwhelming the low, natural background from cosmic ray spallation in the stratosphere. The bomb-tritium signal then entered the surface ocean by precipitation, vapor exchange, and river runoff, providing an excellent tracer of
\end{abstract}

S.C. Doney, Advanced Study Program, National Center for Atmospheric Research, P.O. Box 3000, Boulder, CO 80307, USA; Ph.D. 1991, Woods Hole Oceanographic Institution (advisor: W.J. Jenkins). ocean circulation on time-scales from a few years up to a few decades.

The cold, dense precursors for North
Atlantic Deep Water (NADW) are produced by winter cooling and convection at the surface of the Norwegian/Green-

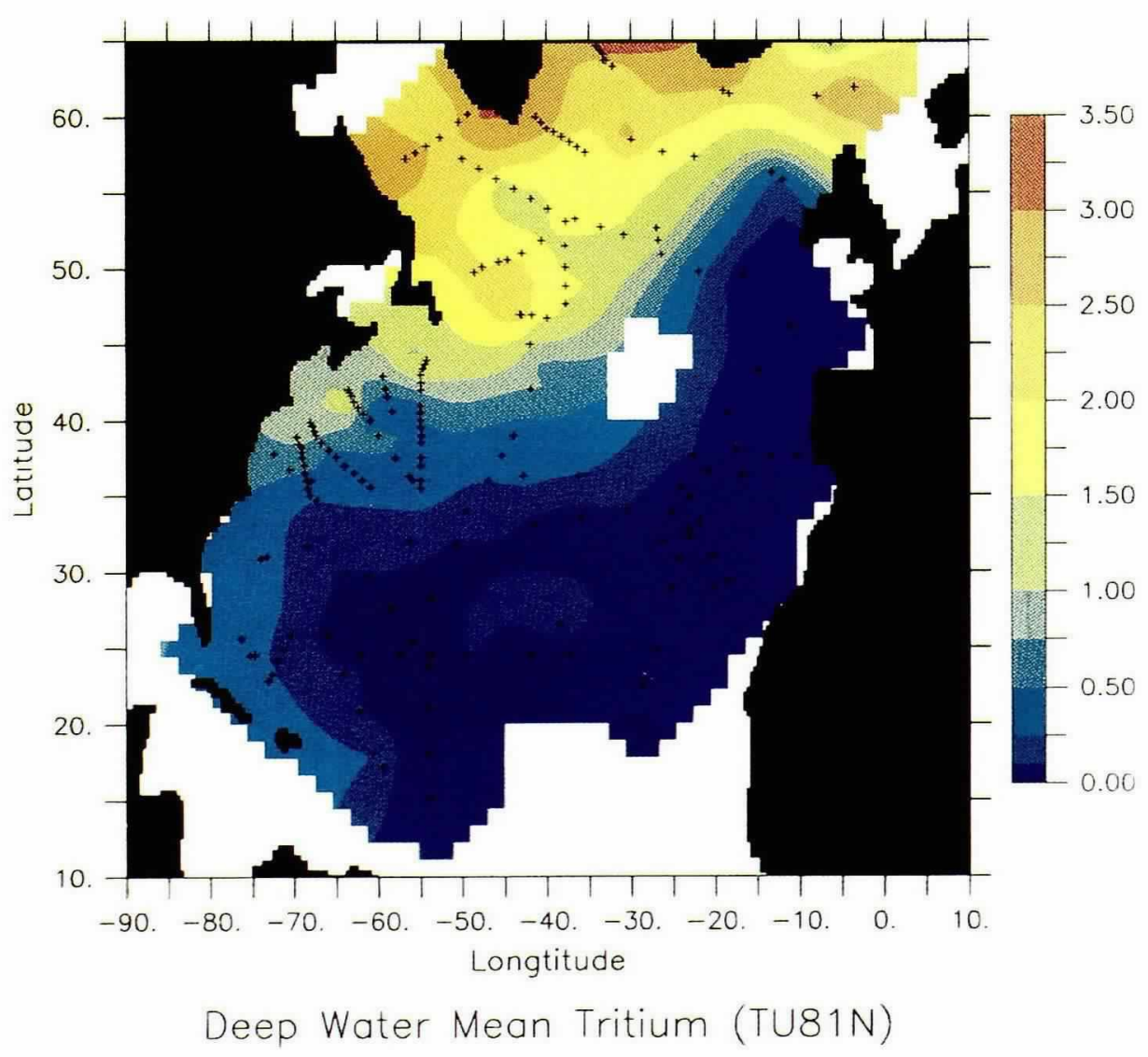

Fig. 1. Contour map of the average tritium concentration in the deep North Atlantic from a composite of cruises in 1981-1983. Deep water is defined by a potential density surface $\left(37.00 \sigma_{2}\right)$ referenced to 2,000 dbars pressure. Tritium concentrations are reported in tritium units (TU), where 1 TU equals 1 tritium atom per $10^{18}$ hydrogen atoms, and are decay corrected to a common date, 1 January 1981. 
land Seas and are tagged with high levels of bomb-tritium from the atmosphere. Based on models and historical data, the tritium content, in a decay corrected sense, of newly formed NADW appears to have increased sharply in the mid1960 s and then remained approximately constant at four tritium units (TU; see Figure 1 caption for definition) until 1981. This allows us to use the distribution of tritium in the deep Atlantic as an analogue for the mixing and spreading of recently formed NADW.

The newly formed deep water spills over several sills in the ridge system separating the Norwegian/Greenland Seas from the North Atlantic and flows westward and equatorward in a series of narrow, deep boundary currents along the eastern margin of North America. These processes are reflected in the large-scale tritium distribution in the deep North Atlantic observed over the period 1981-
1983 (Figure 1), about 15 years after the bomb-tritium pulse. The deep water in the sub-polar gyre is rapidly $\mathrm{O}$ ( 15 years) ventilated by the overflowing NADW, as shown by the high tritium values ( $>1.5$ $\mathrm{TU}$ ) in that region. A tongue of NADW with elevated tritium levels ( $>0.25 \mathrm{TU}$ ) also extends south from the overflow sills along the western boundary. The low tritium water that fills part of the western basin and most of the eastern basin results from the northward flow of older, zero tritium Antarctic Bottom Water.

The tritium concentration in the core of the deep western boundary current decreases by about a factor of $10(4.0-$ $0.35 \mathrm{TU}$ ) from the Labrador Sea to the tropics, and the bulk of the deep-water bomb-tritium (and thus new NADW) resided in 1981 in the Labrador Sea and western subpolar gyre. The subpolar gyre was also the site of the strongest increase $(100 \%)$ in decay-corrected, deep-water tritium levels from the Geochemical Ocean Sections (GEOSECS) survey in 1972 to the TTO survey in 1981.

These observations suggest that the deep western boundary current is quite "leaky": tritium and other tracers introduced into the boundary current are rapidly lost to the interior by turbulent mixing and/or recirculation. From simple model studies, I estimate that on average a water parcel in the boundary current travels $2,500-4,000 \mathrm{~km}$ before being exchanged with interior water. The net affect of recirculation is to increase the ventilation of the deep subpolar gyre and slow the southward spreading rate for newly formed NADW to $1-2 \mathrm{~cm} \mathrm{~s}^{-1}$. These results have important implications for understanding the response of the deep North Atlantic to climatic variability on decadal time scales and the invasion of anthropogenic pollutants (e.g. greenhouse $\mathrm{CO}_{2}$ ) into the deep ocean. 